\title{
dos puentes
}

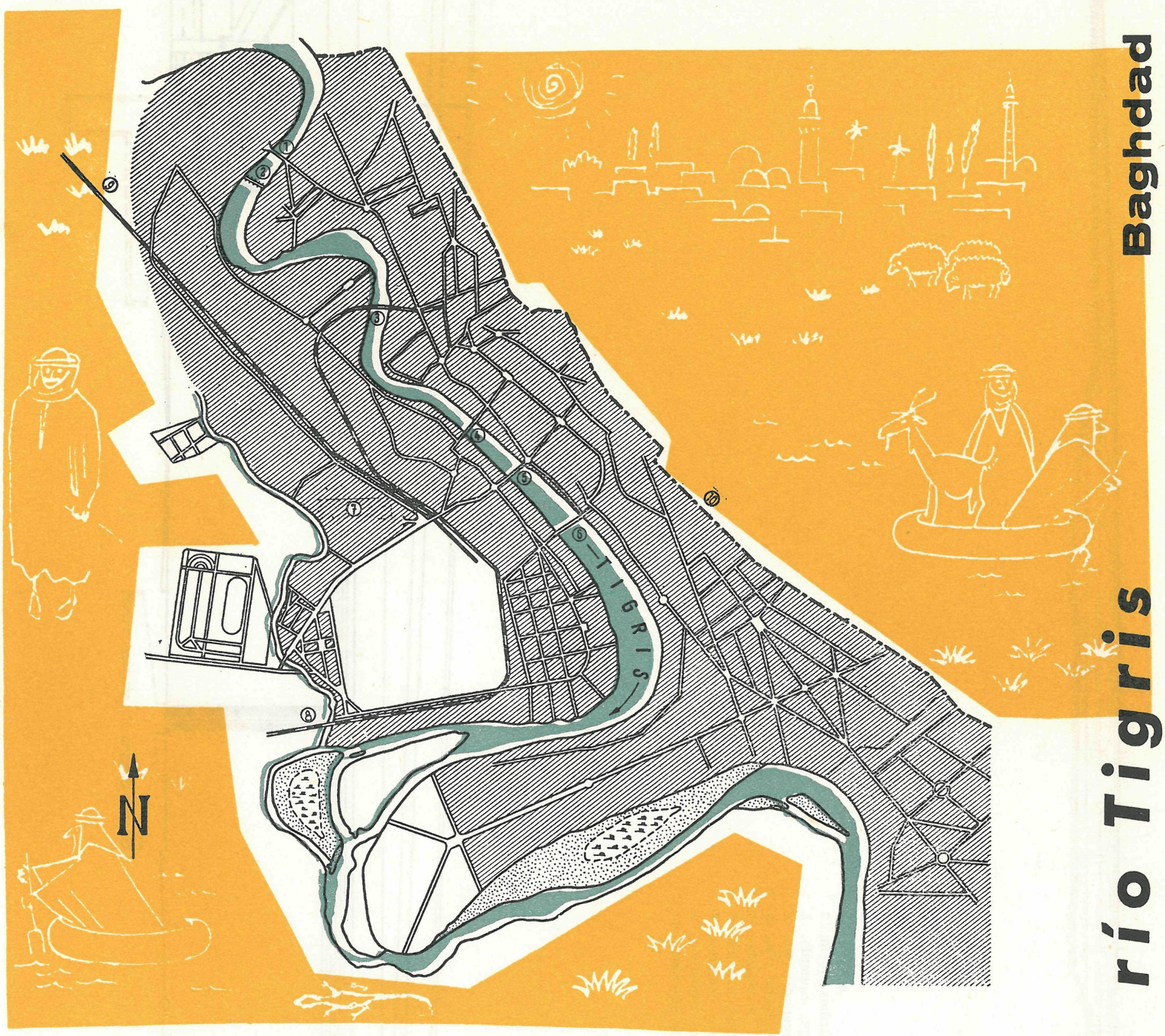

$565 \cdot 9$

Informacion amablemente facilitada por G. H. Vaughan-Lee, ingeniero encargado de la ejecución del proyecto, encomendado a la empresa inglesa Coode and Partners.

En el año 1953 se abrió un concurso público para la adjudicación de dos puentes sobre el rio Tigris, denominados: uno Adhamiyah, y el otro, South Gate, situados dentro del casco urbano de la ciudad de Baghdad, bañada por el río. Anteriormente, sólo existían cuatro puentes para comunicar las dos márgenes del río en una zona de unos $20 \mathrm{~km}$ de longitud según el curso del río, complicando seriamente las comunicaciones y el tráfico creciente entre ambas márgenes. 

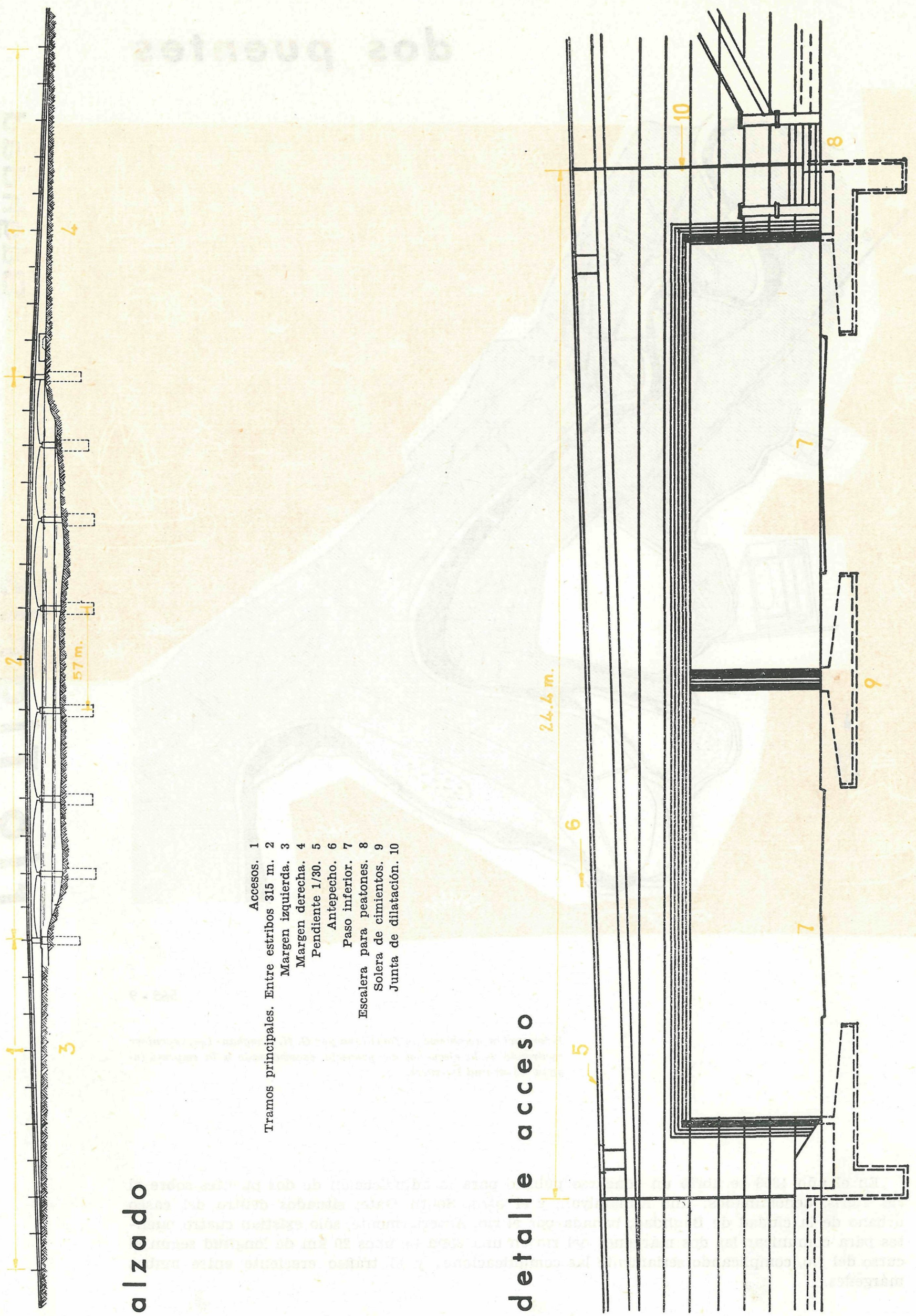


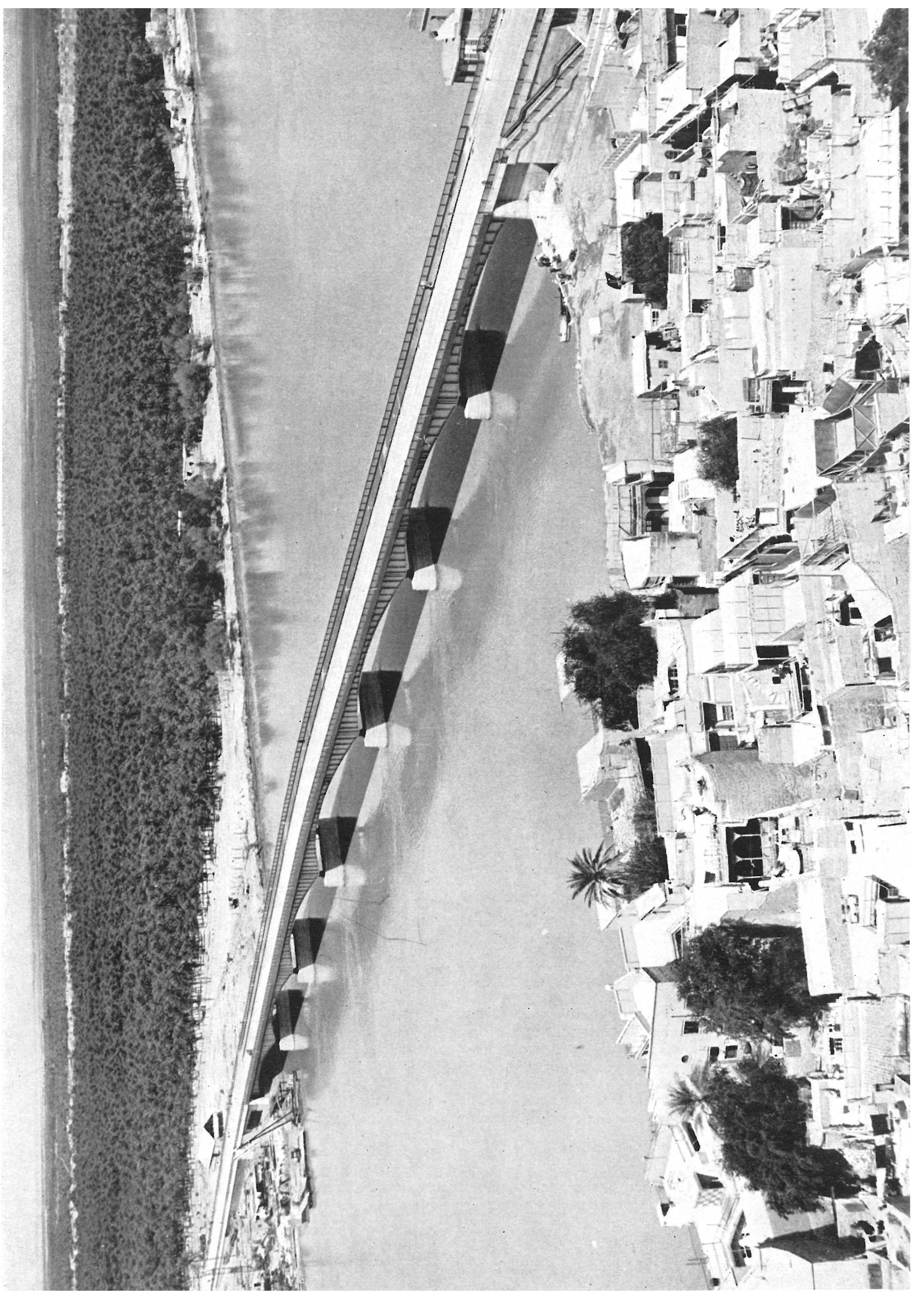




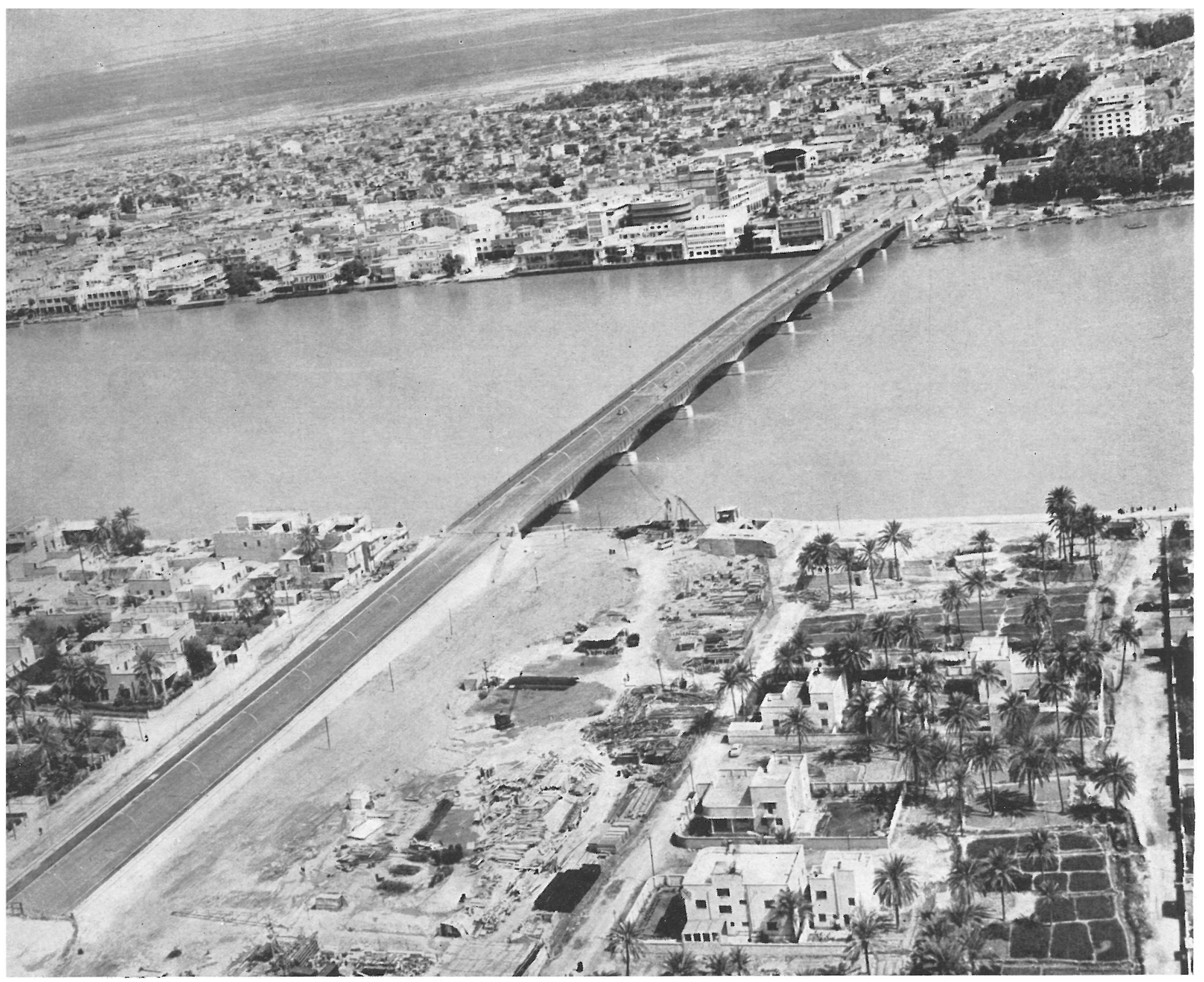

Para remediar el problema, se encargó al gabinete técnico de Coode and Partners, de Londres, la redacción del proyecto para dos nuevos puentes en Baghdad.

La casa Siemens-Bauunion, de Munich, presentó su propuesta de ejecución. Se propuso dos superestructuras metálicas utilizando acero st 52. Los proyectos de ejecución de las empresas alemanas se estudiaron convenientemente, y, finalmente, se les adjudicó la construcción de los dos puentes, empezando rápidamente las obras.

La longitud total del puente South Gate es de unos $772 \mathrm{~m}$; y el de Adhamiyah, de 730. De estos totales, 319 y $413 \mathrm{~m}$ representan, respectivamente, las rampas de acceso.

Los cimientos de los dos puentes se han realizado utilizando cajones. Estos cajones se revistieron con chapa metálica de $6 \mathrm{~mm}$, para protegerlos contra la acción corrosiva del terreno sulfuroso. Las catorce piezas que componen cada uno de los cajones de fondo de los dos puentes, de 5,20 a $17,20 \mathrm{~m}$ de altura, se soldaron en obra con costuras impermeables. 
Los cajones se montaron en la margen del río y a proximidad del puente Adhamiyah, donde se instaló una rampa de lanzamiento con objeto de botarlos al río para su transporte por el mismo, ayudándose de lanchas a motor, hasta el lugar de ubicación. Para disminuir el calado en su transporte, se inyectó aire comprimido en el hueco inferior de la cámara de trabajo. Colocados los cajones en su sitio, guiándolos con pilotes de madera, previamente hincados, se procedió a su anclaje, partiendo de puntos fijos de aguas arriba.

El aire comprimido se suministraba de una central o instalando los compresores sobre pontones. Para la colocación del hormigón se montó una pasarela con elementos tubulares, a los que se soldaron perfiles en forma de doble T. Antes de que se anunciasen las avenidas normales periódicas, se desmontó el entramado tubular de la pasarela.

Como regla general, se hormigonó apoyándose en una central hormigonera. Los áridos se obtuvieron de las distintas graveras del propio río, y otras, complementarias, de graveras del río Diyala, de un lugar a unos $100 \mathrm{~km}$ del puente. El cemento utilizado lo abasteció una fábrica de cemento del país (este cemento tiene las características de los cementos ingleses). Los ensayos de probetas han demostrado que la resistencia obtenida era superior a las que se originan en el Pliego.

Como la madera es cara y escasa en el país se decidió hormigonar con encofrados metálicos, que se encargaron particularmente para estas obras. Estos encofrados han dado un resultado magnífico.

El terreno que sirve de apoyo a la obra es irregular y pobre mecánicamente, puesto que está formado por capas variables, de pequeña potencia, de arena grava y limo. La profundidad que debía descenderse consistió en alcanzar una zona libre de limos y de cascotes.

El proceso de curado húmedo del hormigón presentó un duro problema que había que vencer, ya que es un país cuya temperatura es de $50^{\circ} \mathrm{C}$ a la sombra, de abril a octubre, y un aire de sólo $10 \%$ de humedad.

La superestructura metálica se ciñe concretamente a las directivas trazadas por el gabinete técnico de los ingenieros consultores.

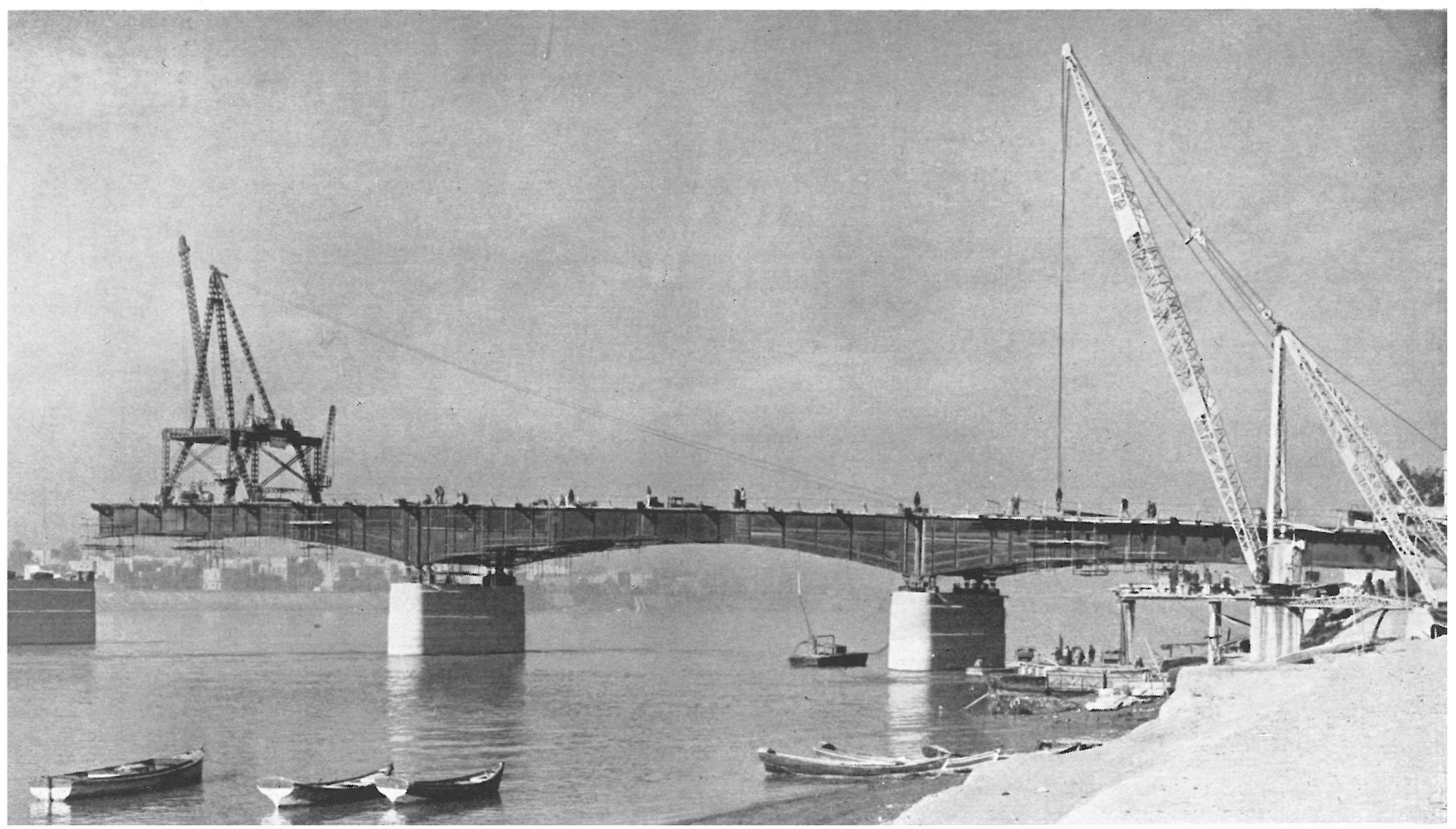




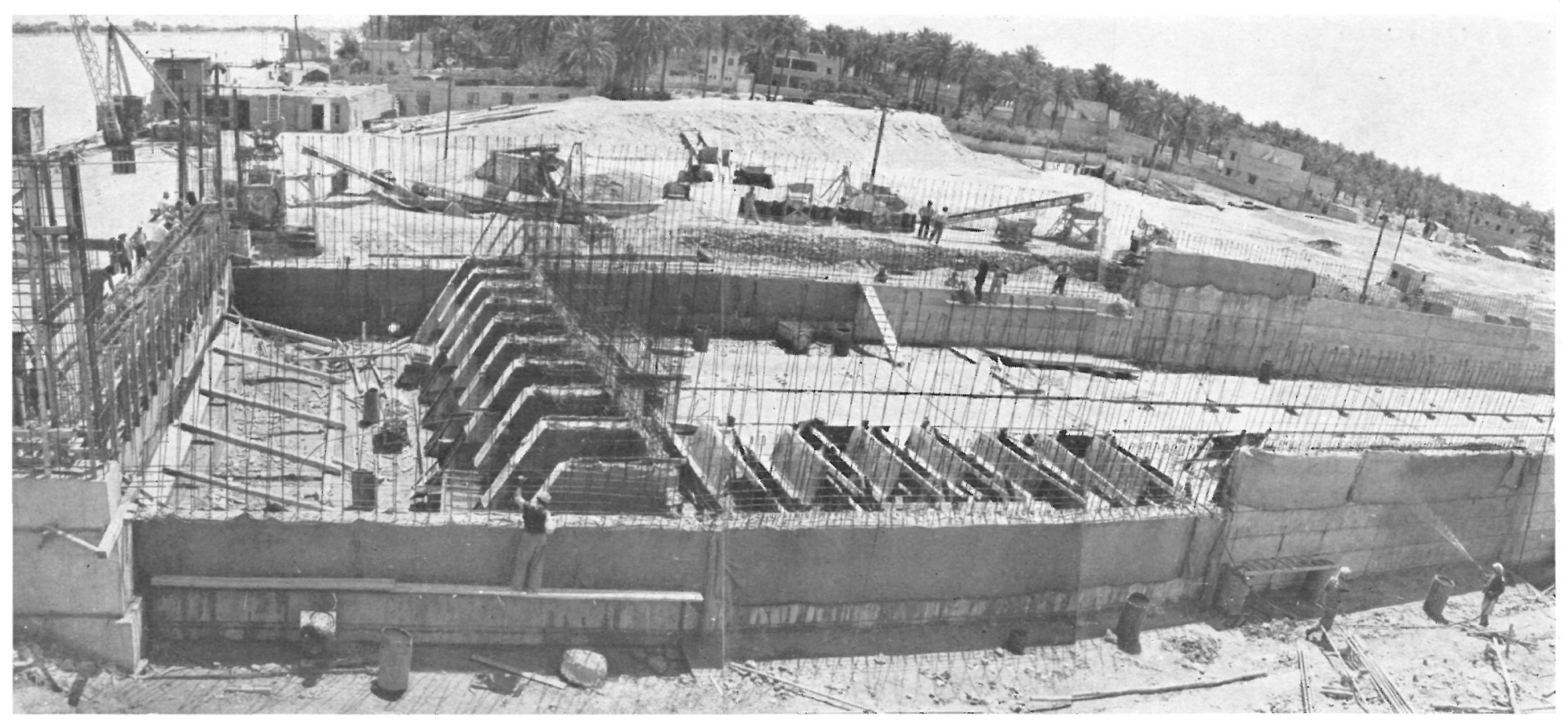

En el puente de Adhamiyah se han empleado 2.400 toneladas de acero y $1.063 \mathrm{~m}^{3}$ de hormigón para la losa de la calzada.

El peso individual de cada trozo de estructura se limitó a ocho toneladas, con objeto de facilitar el transporte y evitar las deformaciones. El montaje de la estructura metálica se hizo siguiendo los procedimientos en voladizo, ayudándose de una grúa de 20 toneladas de capacidad. Los soportes provisionales, utilizados en el montaje, consistieron en castilletes metálicos apoyados sobre pilotes de madera, y en forma tal, que sólo se levantó un castillete entre cada dos pilas. Como el acero se calentaba mucho, debido al sol (hasta $80^{\circ} \mathrm{C}$ ), el montaje sólo se podía llevar a cabo durante las primeras horas de la mañana, y la mayor parte de la soldadura se realizaba durante la noche.

En el puente South Gate se utilizaron 2.135 toneladas de acero y unos $1.752 \mathrm{~m}^{3}$ de hormigón. La estructura de esta obra es del tipo compuesto, y dispone de una losa de hormigón abundantemente armada y de $26 \mathrm{~cm}$ de espesor.

La parte metálica se montó siguiendo los procedimientos de no emplear soportes provisionales, es decir, en voladizo, utilizando, para ello, una grúa, de 20 toneladas de capacidad, que iba avanzando a medida que el montaje así lo requería. Para el hormigonado de la losa sobre el tablero también se utilizó una grúa móvil, montada sobre carriles, para recoger el hormigón de los pontones que lo transportaban.

Los dos andenes de cada uno de estos puentes forman ménsula con las vigas maestras, y se ha dejado debajo suficiente espacio para las canalizaciones de líneas eléctricas y servicios de aguas.

Como la capacidad de sustentación del terreno era muy pobre, se tuvieron que tomar medidas particulares para que los accesos y estribos lograsen las exigencias mínimas exigidas en el Pliego respecto a la estabilidad. Esto fué causa de tener que emplear una serie de pilotes con objeto de obtener mayor capacidad de sustentación en el terreno de apoyo. Los accesos están constituídos por dos muros, entre los cuales se ha rellenado con arena consolidada.

Terminada la obra se realizaron las pruebas de carga: los resultados se admitieron como satisfactorios. 